\title{
INTRODUCTION
}

\section{Police interviews}

\section{Communication challenges and solutions}

\author{
Luna Filipović \\ University of East Anglia
}

We have two primary goals in this collection: (a) to reveal, exemplify and explain a number of communication and situational phenomena that characterise police interviews and (b) to illustrate how linguistic pragmatic theories enable us to understand these phenomena better and make some suggestions that may improve professional practice. The communicative context of police interviews is characterised by high sensitivity, prominent differences in power relations and a clear communicative goal of eliciting information of relevance to an investigation. These defining parameters create a unique discourse framework that is different from everyday communicative contexts, yet also similar to them in a number of ways. In spite of the restrictiveness of the police interview context, the usual conversation rules and strategies still apply and they can still be respected or broken, just like in any normal conversational exchange. Therefore, pragmatics has been the chosen backdrop for a number of studies of police communication in general, and police interviews in particular. For instance, Linfoot-Ham (2006) analysed authentic exchanges between police officers and suspects and illustrated how the Gricean Cooperative Principle and the related maxims can help us draw inferences about the communicative goals of interlocutors, such as deceit or avoidance of responsibility. In another extensive study of police interview interactions, Heydon (2005) discusses numerous examples that illustrate how power-relations are established and maintained in discourse, including turn-taking, topic control and flow management.

In spite of substantial interest in police interview research in linguistics, sociology, psychology and legal studies, there was still a gap in our knowledge about the specific linguistic devices and concrete expressive patterns and structures that are crucially responsible for the specific communicative effects in police interviews or for their outcomes. In other words, a detailed, finely grained linguistic analysis comprising all levels at which meaning is conveyed (lexical semantic, syntactic, and discourse) would make it possible to capture the many different processes that 
characterise police interview communication. This is precisely why the present collection offers a multi-perspective view of what happens in police interviews.

The police interview is a complex communicative situation and a single perspective in the analysis will not do. For this reason the present study adopts an original approach to the study of police interviews whereby the same datasets are studied from a variety of angles within applied pragmatics research (see papers by De Pablos-Ortega, Filipović, Musolff and Pounds). Furthermore, the collection includes cross-linguistic analyses of interpreted-assisted police interviews, with data from both UK and the US, which provide an additional angle from which we can observe the complexities of this specific communicative situation (see papers by Filipović and Hijazo-Gascón). Finally, while multilingual police interviews are rarely analysed in detail in the literature, with a few notable exceptions (e.g. BerkSeligson 2002, 2011; Filipović 2007, 2013; Filipović and Hijazo-Gascón 2018; Filipović and Abad Vergara 2018), the present study allows us to catch a glimpse of how police officers and interpreters feel about working with each other and how communication outcomes may be affected by the different assumptions these agents hold with regard to their roles, to issues of trust, and to the management of emotions during and after an interview (see paper by Wilson and Walsh).

Another novelty in the present collection is its focus on previously rarely mentioned yet very relevant aspects of police communication in interviews, namely, the use and role of metacommunication, empathy and face, the balance between mitigation and aggravation strategies, and the communicative effect of negative and complex questions. We believe that our collection provides an original and comprehensive contribution to both applied pragmatics research and more specifically to the study of interaction in this specific, socially relevant context of police interviews.

Most of the research presented in this collection, unless indicated otherwise, was carried out as part of the TACIT Project (Translation and Communication in Training), conducted at the University of East Anglia in collaboration with two UK police constabularies, to whom we are immensely grateful. This collaboration enables us to work with unique and extensive datasets, otherwise rarely available to academics.

Our gratitude also goes to the Public Defence Attorney's Office in the State of California (USA) as well as a number of US court and police interpreters from San Francisco, San José and Oakland, who shared transcripts of authentic police interviews with us for the purpose of our analyses. We also want to express our gratitude to the UK Economic and Social Research Council (ESRC) for the support from the Impact Acceleration Fund that enabled us to engage with our stakeholders and gain the knowledge about good practice and professional training needs which inspired this research. 
Finally, our thanks go to Professor Ning Ye of Zhejiang Police College, PRC, for the positive and encouraging review of our work, and to Jacob and Inger Mey for superb editorial work and steadfast support throughout the preparation of this volume for publication. We now turn to introducing each chapter.

The paper by Musolff 'You keep telling us different things, what do we believe?' - Meta-communication and meta-representation in police interviews is an initial exploration into the role of quotations and other forms of metarepresentation in police interviews with suspects. The conflicting responses or accounts in suspects' narratives can be used by interrogating officers as a trigger to elicit new interpretations that explain inconsistencies and thus ideally prompt suspects 'to finally tell the truth'. In linguistic pragmatics, such commenting can be categorised as metacommunication (i.e. 'communication about communication') that includes metarepresentation, i.e. second-order representation of another representation through some form of quotation. The instances of metacommunication are key-moments of negotiating the communicative interests of the chief participants in the interview interaction, i.e. on the one hand the interviewers', whose purpose is establishing grounds for a potential criminal charge and, on the other hand, the interviewees', whose intention is avoiding or resisting such a charge. Musolff notes that there is a danger of a breakdown of rapport when an interviewee's statements are criticised as wrong or deliberately deceptive on account of a discrepancy with preceding statements, and that a way of avoiding that breakdown is to act with awareness about the metacommunicative function of their interventions. He illustrates two different approaches to metacommunication and their different effectiveness and success in evidence elicitation and rapport-building and maintenance.

The article by De Pablos-Ortega 'Would it be fair to say that you actively sought out material?' - Mitigation and aggravation in police investigative interviews focuses on specific linguistic devices that are used for the purpose of mitigating vs. aggravating statements by police officers. The author's original proposal for a taxonomy of these devices provides us with a tool for the analysis of their types and functions. The findings reveal that more mitigation than aggravation strategies were used in police questioning and statements during the interviews. It was found that mitigation was used as a device for alleviating or attenuating the illocutionary force of questions and statements with a view to increasing the solidarity of the relationship between police officers and suspects ("positive face want") and build rapport. Finally, the paper reveals that the determinant factor for the use of mitigation and aggravation devices is the type of offence, as the presence of sensitive issues, such as sexual offences, leads to a higher number of devices in the exchanges. This implies that police officers' questions and statements include mitigation devices more frequently in order to attenuate the effect of what can be 
regarded as a delicate or compromising matter during the interviews for sexual offences. An important path for further study is laid out here, namely the need to explore the effects of mitigation and aggravation on responses by suspects and on the quality and quantity of information elicited.

The article by Pounds, Rapport building in police interviews with suspects: The role of empathy and face demonstrates the value of using a discourse-pragmatic analytical approach to the systematic exploration of rapport, specifically empathy and face-relevant expressive dimensions in police interviews. Pounds draws attention to the bi-functionality of these expressions, i.e. to the fact that they may $b e$, and in fact are used both to retrieve essential investigation-relevant information (an instrumental value) and to build and maintain rapport (an ethical value). Whilst to some extent, this bi-functionality may be relevant in most professional contexts, it is particularly apparent in police interviews with suspects, due to the way in which the two functions are often difficult to reconcile and integrate. Of special significance is the author's mixed methods approach, combining detailed linguistic analysis with observational investigation of official police training and practice. This enables her to identify more attainable uses of rapport than was possible in previous research focusing on linguistic analysis only. In particular, Pounds' study provides novel and authentic insights into empathy-specific responses, pointing to the value of acknowledging feelings, expressing a degree of positive regard, and even some limited forms of solidarity and affiliation. It further explores how rapport may not be completely compromised at the stage of the interview when the interviewer has to challenge the information given. The article also includes a rapport aid memoir that may be used by interviewers in training and practice.

A number of linguistic complexities that characterise police interviews and create sources of misunderstanding and miscommunication are addressed in the paper by Filipović entitled Police interviews with suspects: Communication problems in evidence-gathering and possible solutions. Interviews with suspects involve a special additional layer of complexity in communicative exchanges, which is driven by the fact that the basic principle of conversation, cooperation (Grice 1975), is very likely not to be respected and is sometimes severely and purposefully violated, for example when suspects are guilty and want to obscure that fact, or when they believe that their situation would worsen if they cooperated with the police. An even deeper layer of complexity is added when the interviews are carried out via an interpreter, where the fact that the officer and the suspect speak different languages during the interview creates additional barriers to straightforward communication. Filipović illustrates a number of identified points at which difficulties in communication arise in this highly sensitive legal context, such as the linguistic complexity in police statements-as-questions, the difficulty in the processing 
of negative polar questions and the unresolved ambiguities in the source language that are left to the interpreter to solve. She demonstrates the real-life effects of these difficulties and suggests concrete actions that could prevent communication breakdowns.

The paper by Hijazo-Gascón Translating accurately or sounding natural? The interpreters' challenges due to semantic typology and the interpreting process is focused specifically on the cross-linguistic issues that arise in multilingual police interviews. Using authentic samples from the United States, where police interview transcripts are verbatim and bilingual, Hijazo-Gascón highlights the discrepancies found between the interpreter present in the interrogation, and the control interpreter who checks and transcribes the interview. The results show different types of inaccuracies in the interpretation, which can be attributed to two sources: (1) interpreting-skills related challenges (time pressure, tendency to neutral speech, focus on key informational content at the expense of pragmatic content, such as modularity and rapport-building), and (2) typological differences between the two languages involved. The first type of difficulties results in loss of pragmatic information, such as loss or increase of illocutionary strength, direct translation of euphemisms, oversimplifications and other inaccuracies. The second group of discrepancies are due to the contrasts between the specific pair of languages involved in the interpreting process at the levels of agency, intentionality, manner of motion, modal verbs, deixis and information. In such cases, the conundrum is whether to render a more natural translation with addition or omission of information, or to render a more literal translation, with the risk of sounding unnatural and adding social and pragmatic connotations that are not present in the original. Hijazo-Gascón proposes that Applied Language Typology (Filipović 2017a, 2017b) be used as a framework for analysis and evaluation of these problematic interpretations, and that training guidelines should include a focus on the effects of typological differences between languages in concrete situations relevant for professional practice.

Finally, the paper by Wilson and Walsh, Striving for impartiality: Conflicts in interpreter-assisted police interviews, provides an authentic insight into the complex array of potential and real conflicts that characterise interpreter-assisted police interviews. The authors investigate the perceptions of the different participant roles (of interviewing officers and interpreters respectively) and the related attitudes and emotions that are experienced during the performance of their communicative duties in the police interviewing. While this work does not focus on linguistic features, it provides a broader characterisation of the interview as a highly specific and complex communicative context and highlights the importance of addressing and clarifying the roles and emotional status of the participants. This research also fulfils one of the missions of the present collection, 
namely the aim to provide a multifaceted view of the complexities that characterise communicative exchanges in police interviews. The study also proposes lines for further investigations into the possibility that the relationship between officers and interpreters, as well as into emotional aspects of interviewing and interpreting in this context that may affect the accuracy and quality of the information elicited in police interviews. The authors formulate a concrete proposal for a better kind of briefing and debriefing, one that forges a collaborative relationship between the interpreter and the police officer - a collaboration that does not just kick in when a problem is detected.

\section{Avenues for further research in this area}

There are many directions for future empirical investigations. An especially interesting line for further enquiry would be a comparison between the communicative styles of UK and US police officers respectively, while also considering data from other countries that follow one or the other approach. The different regulations for police communication determine the pragmatic aspects of communication (including the ones discussed in this volume) differently by creating different interactive environments which may have different communication outcomes. When the goals of communication differ, e.g. to elicit a confession (US) vs. to gather information (UK), the linguistic roadmap to achieving each goal is likely to be different too, even though there may be some overlaps that arise when either the interrogation (US) and the interview (UK) method is used. In particular, understanding how language use may differ based on the different legal contexts as well as and the related different communication goals, would enable us to gain new insight into the interactional nature of meaning and its context-dependence (see Jaszczolt 2016 for the latest theoretical developments).

Another direction of future research would be a large-scale contrastive comparison of monolingual and interpreter-assisted police interviews in order to determine whether there is equality in the quality of service, as well as what difficulties are shared across the board as opposed to what may pertain to the interview contexts (monolingual or bilingual. Additionally, the pragmatic domains of language use tackled in this volume need to be further looked at through a cross-linguistic prism, insofar as they bear relevance to communication in police investigation and may have different guises in different languages and cultures. Prospective cross-linguistic and cross-cultural research will significantly enhance our understanding of the multiple dimensions that are involved in communication during police interviews and impact information exchange in that highly sensitive context; such understanding is likely to extend our knowledge of cross- 
cultural pragmatics and its applications, while at the same time contributing practical benefits to professionals such as police officers and interpreters in the UK, the US, and beyond.

\section{References}

Berk-Seligson, Susan. 2002. "The Miranda Warnings and Linguistic Coercion: The Role of Footing in the Interrogation of a Limited-English Speaking Murder Suspect". In Language in the Legal Process, ed. by Janet Cotterill, 127-143. New York: Palgrave Macmillan. https://doi.org/10.1057/9780230522770_8

Berk-Seligson, Susan. 2011. "Negotiation and Communicative Accommodation in Bilingual Police Interrogations: A critical Interactional Sociolinguistic Perspective". International Journal of the Sociology of Language 207: 29-58.

Filipović, Luna. 2007. "Language as a Witness: Insights from Cognitive Linguistics". International Journal of Speech, Language and the Law 14 (2): 245-267. https://doi.org/10.1558/ijsll.v14i2.245

Filipović, Luna. 2013. "The role of Language in Legal Contexts: A Forensic Cross-linguistic Viewpoint". In Law and Language: Current Legal Issues (15), ed. by Michael Freeman and Fiona Smith, 328-343. Oxford: Oxford University Press. https://doi.org/10.1093/acprof:oso/9780199673667.003.0167

Filipović, Luna. 2017a. “Applied Language Typology: Applying Typological Insights in Practice”. Languages in Contrast 17(2): 255-278. https://doi.org/10.1075/lic.17.2.05fil

Filipović, Luna. 2017b. “Applying Language Typology: Practical Applications of Research on Typological Contrasts between Languages". In Motion and Space across Languages. Theory and Applications, ed. by Iraide Ibarretxe-Antuñano, 399-418. Amsterdam: John Benjamins. https://doi.org/10.1075/hcp.59.16fil

Filipović, Luna, and Alberto Hijazo-Gascón. 2018. "Interpreting Meaning in Police Interviews: Applied Language Typology in a Forensic Linguistics Context”. Vigo International Journal of Applied Linguistics VIAL 15: 67-103.

Filipović, Luna and Suzanne Abad Vergara. 2018. "Juggling Investigation and Interpretation:

The Problematic Dual Role of Police Officer-Interpreter". Law and Language/ Linguagem e Direito 5(1): 62-79.

Heydon, Georgina. 2005. The Language of Police Interviews: A Critical Analysis. Basingstoke: Palgrave Macmillan. https://doi.org/10.1057/9780230502932

Jaszczolt, Kasia. 2016. Meaning in Linguistic Interaction: Semantics, Metasemantics, Philosophy of Language. Oxford: Oxford University Press.

Kredens, Krysztof. 2016. Making sense of adversarial interpreting. Unpublished ms. Aston University.

Linfoot-Ham, Kerry. 2006. "Conversational Maxims in Encounters with Law Enforcement Officers". The International Journal of Speech, Language and the Law 13(1): 23-54. https://doi.org/10.1558/sll.2006.13.1.23 
Meissner, Christian A., Allison R. Redlich, Stephen W. Michael, Jacqueline R. Evans, Catherine Camilletti, Sujeeta Bhatt, and Sussan Brandon. 2014. "Accusatorial and Information-gathering Interrogation Methods and their Effects on True and False Confessions: A meta-analytic Review". Journal of Experimental Criminology 10: 459-486. https://doi.org/10.1007/s11292-014-9207-6

\section{Author Queries}

- Please provide a complete reference for the citation '(Grice 1975)' in this article.

- Please provide a citation for the reference id "CIToo11 (Kredens, Krysztof. 2016), CIToo13 (Meissner, Christian A., Allison R. Redlich, Stephen W. Michael, Jacqueline R. Evans, Catherine Camilletti, Sujeeta Bhatt, and Sussan Brandon. 2014)" since citation is missing in the article. 